\title{
PENGARUH KOMPETENSI, MOTIVASI DAN KOMUNIKASI TERHADAP KINERJA KARYAWAN PADA RUMAH SAKIT SWASTA DI KOTA BATAM
}

\author{
Wasiman \\ Universitas Putera Batam
}

\begin{abstract}
This study aims to see the influence of competence, motivation and communication on employee performance at private hospitals in Batam City. The study used a questionnaire distributed to employees of private hospitals in Batam City with a questionnaire of 250 respondents. This study uses an individual level analysis. The research object is employees of private hospitals in Batam City. This study uses multiple linear regression tests which include validity, reliability, normality, and $r$ square tests. The results show that based on the results of the validity test, it shows that all the research indicators show the validity results, which means that it can show to the next stage, and also the reliability test results conclude that all the data collected and processed are reliable. The coefficient of determination (R2) is 0.840 , which means that the performance variable can serve the leadership style, motivation and communication variables by $84 \%$, while the remaining is $16 \%$. \% evidence by factors not present in this study.
\end{abstract}

Keywords: Competence, Motivation, Communication and Employee performance

\section{PENDAHULUAN}

Era globalisasi untuk saat ini memaksa semua perusahaan untuk terus berusaha menciptakan sumber daya manusia yang memadahi dan dapat bersaing dengan perusahaan global. Kompetensi yang dimiliki oleh karyawan perusahaan harus dapat menjawab tantangan yang semakin komplek untuk terus berusaha menciptakan persaingan saat ini. Rumah sakit untuk saat ini mempunyai tanggung jawab yang besar dalam usaha untuk meningkatkan kompetensi yang dimiliki oleh karyawan dalam menangani kondisi covid 19 yang semakin tidak kunjung mereda.

Menurut Moehariono (2018: 78) kompetensi merupakan karakteristik yang mendasari seseorang berkaitan dengan efektivitas kinerja individu dalam pekerjaan tau karakteristik dasar individu yang memiliki hubungan kausal atau sebab-akibat dengan kriteria yang dijadikan acuan, efektif atau berkinerja prima atau superior ditempat bekerja pada organisasi. Kompetensi dikatakan sebagai karakteristik dasar karena karakteristik individu merupakan bagian yang mendalam dan melekat pada kepribadian seseorang yang dapat dipergunakan untuk memprediksi berbagai situasi pekerjaan tertentu. Kemudian dikatakan berkaitan antara perilaku dan kinerja karena kompetensi menyebabkan atau dapat memprediksi perilaku dan kinerja.

Sedarmayanti (2019: 9) motivasi adalah suatu faktor yang mendorong seseorang untuk melakukan aktivitas tertentu, oleh karena itu motivasi sering kali diartikan pula sebagai faktor pendorong aktivitas. Motivasi merupakan hal yang sangat penting untuk diperhatikan oleh pihak manajemen bila mereka menginginkan setiap karyawan dapat memberikan kontribusi positif terhadap pencapaian tujuan perusahaan.

Komunikasi dimaknai sebagai jalannya proses dimana seseorang maupun sekelompok orang menciptakan serta menggunakan sejumlah informasi agar saling terhubung dengan lingkungan sekitar. Secara umum komunikasi dapat dilakukan secara verbal serta dapat dipahami oleh kedua belah pihak berkaitan. 
Beberapa masalah yang timbul dengan dan menarik peneliti antara lain adanya kompetensi karyawan rumah sakit yang masih rendah, motivasi yang menurun. Kurangnya komunikasi hal ini mengakibatkan adanya gap antara atasan dan bawahan. Berdasarkan uraian diatas maka perlu dilakukan penelitian dengan judul Pengaruh Kompetensi, Motivasi Dan Komunikasi Terhadap Kinerja Karyawan Pada Rumah Sakit Swasta di Kota Batam.

\section{KAJIAN PUSTAKA}

\section{Kompetensi}

Menurut Robbin (2018: 78) kompetensi adalah kemampuan atau kapasitas seseorang untuk mengerjakan berbagai tugas dalam suatu pekerjaan, dimana kemampuan ini ditentukan oleh dua faktor yaitu kemampuan intelektual dan kemampuan fisik. Menurut Mangkunegara (2017: 40) kompetensi sumber daya manusia adalah kompetensi yang berhubungan dengan pengetahuan, keterampilan, kemampuan dan karakteristik kepribadian yang mempengaruhi secara langsung terhadap kinerjanya.

Kompetensi dapat digambarkan sebagai kemampuan untuk melaksanakan satu tugas, peran atau tugas, kemampuan mengintegrasikan pengetahuan, ketrampilan-ketrampilan, sikapsikap dan nilai-nilai pribadi, dan kemampuan untuk membangun pengetahuan dan keterampilan yang didasarkan pada pengalaman dan pembelajaran yang dilakukan. Menurut Robin (2016: 78) terdapat tiga indikator kompetensi yaitu sebagai berikut: 1). Pengetahuan; 2). Keterampilan; 3). Pengalaman.

\section{Motivasi}

Motivasi didalam pribadi orang, akan berpengaruh langsung terhadap tindakan yang akan dilakukannya. Karena motivasi merupakan kekuatan yang ada didalam diri seseorang untuk berbuat sesuatu yang dapat memuaskan keinginannya. Menurut Samsudin (2015: 88) motivasi adalah suatu faktor yang mendorong seseirang untuk melakukan aktivitas tertentu, oleh karena itu motivasi sering kali diartikan pula sebagai faktor pendorong aktivitas tersebut.

Menurut Sunyoto (2014: 109) motivasi adalah serangkaian sikap dan nilai-nilai yang mempengaruhi individu untuk mencapai hal yang spesifik sesuai dengan tujuan individu. Sikap dan nilai tersebut merupakan suatu yang invisible yang memberikan kekuatan untuk mendorong individu untuk bertingkah laku dalam mencapai tujuan. Menurut Sunyoto (2014: 184) indikator yang digunakan untuk mengukur motivasi adalah sebagai berikut : 1). Tanggung Jawab Terhadap Pekerjaan; 2). Kebutuhan rasa aman; 3). Keterampilan; 4). Kebutuhan harga diri; 5). Kebutuhan pengembangan diri.

\section{Komunikasi}

Menurut Bangun (2012: 360) komunikasi merupakan alat yang sangat penting untuk menyampaikan atau menerima informasi kepada atau dari pihak lain. Sedangkan menurut Wibowo (2014: 241) menyatakan komunikasi adalah pertukaran informasi antara sender dan receiver, dan menarik kesimpulan sebagai persepsi tentang makna sesuatu antara individual yang terlibat. Menurut Robin. (2014: 110) terdapat lima indikator komunikasi yaitu: 1). Pemahaman; 2). Kesenangan; 3). Pengaruh pada sikap; 4). Hubungan yang makin baik; 5). Tindakan.

\section{Kinerja Karyawan}

Menurut Robin (2017: 85) kinerja adalah proses komunikasi yang sedang berjalan, dilakukan dengan kemitraan antara pekerja dengan atasan langsung mereka, yang menyangkut menciptakan harapan jelas dan saling pengertian tentang pekerjaan yang harus dilakukan. Menurut Robin (2017: 88) terdapat tujuh indikator kinerja karyawan sebagai berikut: 1). Tujuan; 2). Standar; 3). Umpan Balik; 4). Alat atau Sarana; 5). Kompetensi; 6). Motif; 7). Peluang. 


\section{Kerangka Pemikiran}

Dari uraian diatas, maka dapat dibuat suatu kerangka pemikiran sebagai berikut:

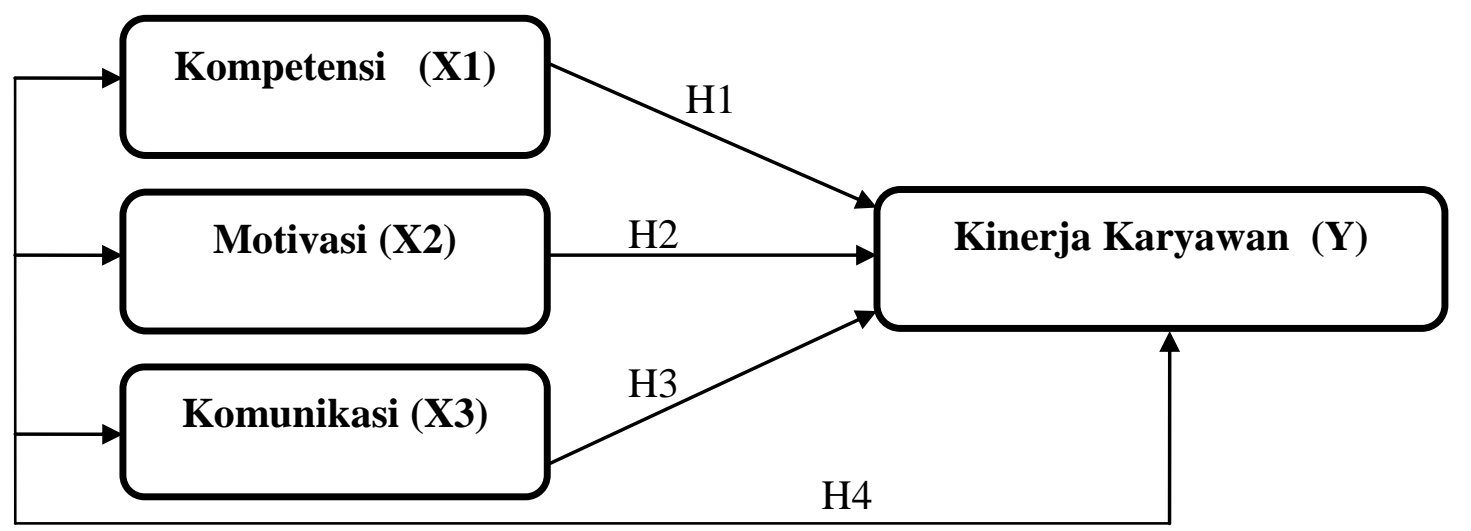

\section{Hipotesis}

Berdasarkan kerangka pemikiran serta tinjauan pustaka yang jelaskan diatas maka hipotesis dari penelitian ini adalah:

$\mathrm{H}_{1}$ : Kompetensi berpengaruh signifikan terhadap kinerja karyawan pada Pada Rumah Sakit Swasta di Kota Batam

$\mathrm{H}_{2}$ : Motivasi berpengaruh signifikan terhadap kinerja karyawan pada Rumah Sakit Swasta di Kota Batam

$\mathrm{H}_{3}$ : Komunikasi berpengaruh terhadap kinerja karyawan pada Rumah Sakit Swasta di Kota Batam

$\mathrm{H}_{4}$ : Kompetensi, Motivasi dan komunikasi secara bersamaan berpengaruh signifikan terhadap kinerja karyawa pada Rumah Sakit Swasta di Kota Batam

\section{METODE PENELITIAN}

\section{Desain Penelitian}

Menurut Sugiyono (2014: 88) Desain penelitian adalah kerangka atau cetak biru dalam melaksanakan proyek riset. Rencana penelitian mencakup garis besar dari apa yang akan dilakukan seorang penelitian mulai dari penulisan hipotesis serta implikasi operasionalnya sehingga ke analisis akhir data. Lokasi penelitian adalah Rumah Sakit Swasta di Kota Batam

\section{Populasi Dan Sampel}

Populasi yang digunakan sebanyak 250 responden dengan menggunakan rumus Slovin dengan tingkat kesalahan yang ditoleransi 5\%, sedangkan sampel yang digunakan sebanyak 250 responden.

\section{HASIL PENELITIAN DAN PEMBAHASAN}

\section{Profil Responden} berikut:

Hasil analisis responden berdasarkan jenis kelamin dapat dilihat pada tabel sebagai 
Tabel 4.1 Profil Responden Berdasarkan Jenis Kelamin

\begin{tabular}{|c|c|c|c|}
\hline No & Keterangan & Frequency & Percent \\
\hline 1 & Laki-laki & 110 & 35,8 \\
\hline 2 & Perempuan & 140 & 64,2 \\
\hline & Total & 250 & 100,0 \\
\hline
\end{tabular}

Sumber: Hasil Olah Data Primer

Berdasarkan hasil table 4.1 dapat diketahui bahwa total penelitian ini berjumlah 250 responden, jumlah responden laki-laki sebanyak 110 orang dengan persentase $35,8 \%$ dan jumlah responden perempuan sebanyak 140 orang dengan persentase 64.2\%. Hal ini menunjukkan bahawa responden perempuan lebih banyak dibandingkan dengan responden lakilaki.

Uji vadilitas variable Kompetensi $\left(\mathbf{X}_{1}\right)$

Hasil olah data validitas dapat dilihat tabel 4.2 di bawah ini:

Tabel 4.2 Hasil Uji Validitas Kompetensi $\left(\mathrm{X}_{1}\right)$

\begin{tabular}{|c|c|c|c|}
\hline \multicolumn{3}{|c|}{ Kompetensi } \\
\hline Pernyataan & r-hitung & r-tabel & Keterangan \\
\hline X1_1 & 0,770 & & Valid \\
\hline X1_2 & 0,801 & \multirow{2}{*}{0,2079} & Valid \\
\hline X1_3 & 0,792 & & Valid \\
\hline
\end{tabular}

Sumber: Hasil Olah Data SPSS Versi 21

Berdasarkan Tabel 4.2 diatas, dapat dilihat bahwa nilai $\mathrm{r}_{\text {hitung }}$ untuk semua pernyataan variable $X_{1}$ lebih besar dibandingkan dengan nilai $r_{\text {tabel }}(\mathrm{Df}=123)$. Dengan demikian, seluruh pernyataan variable Kompetensi $\left(\mathrm{X}_{1}\right)$ dinyatakan valid dan dapat digunakan dalam pengujian selanjutnya.

Uji vadilitas variabel Motivasi $\left(\mathbf{X}_{2}\right)$

Tabel 4.3 Hasil Uji Validitas Motivasi $\left(\mathrm{X}_{2}\right)$

\begin{tabular}{|c|c|c|c|}
\hline & r-hitung & r-tabel & Keterangan \\
\hline Xnstrumen & 0.820 & & Valid \\
X2.2 & 0.684 & 0.2079 & Valid \\
X2.3 & 0.740 & & Valid \\
X2.4 & 0.701 & & Valid \\
X2.5 & 0.740 & & Valid \\
\hline
\end{tabular}

Berdasarkan tabel 4.3 dapat dilihat bahwa semua pernyataan variabel dinyatakan valid karena lebih besar dibandingkan dengan nilai $r_{\text {tabel }}(\mathrm{Df}=123)$. Dengan demikian, seluruh pernyataan variable Motivasi (X2) dinyatakan valid dan dapat digunakan dalam pengujian selanjutnya. 
Uji vadilitas variabel Komunikasi (X3)

Tabel 4.4 Hasil Uji Validitas Komunikasi $\left(\mathbf{X}_{3}\right)$

\begin{tabular}{|c|c|c|c|}
\hline \multicolumn{3}{|c|}{ Komunikasi } \\
\hline Pernyataan & r-hitung & r-tabel & Keterangan \\
\hline X2_1 & 0,744 & & Valid \\
\hline X2_2 & 0,707 & \multirow{2}{*}{0,2079} & Valid \\
\hline X2_3 & 0,724 & & Valid \\
\hline X2_4 & 0,711 & & Valid \\
\hline X2_5 & 0,805 & & Valid \\
\hline
\end{tabular}

Sumber: Data primer

Berdasarkan Tabel 4.4 di atas, dapat dilihat bahwa nilai $\mathrm{r}_{\text {hitung }}$ untuk semua pernyataan variabel $\mathrm{X}_{2}$ lebih besar dibandingkan dengan nilai $r_{\text {tabel }}$ senilai 0,2079 (df $\left.=123\right)$. Dengan demikian, seluruh pernyataan variabel komunikasi (X3) dinyatakan valid dan dapat digunakan dalam pengujian selanjutnya.

\section{Uji validitas variabel kinerja karyawan (Y)}

Tabel 4.5 Hasil Uji Validitas Kinerja Karyawan (Y)

\begin{tabular}{|c|c|c|c|}
\hline \multicolumn{3}{|c|}{ Kinerja Karyawan } \\
\hline Pernyataan & r-hitung & r-tabel & Keterangan \\
\hline Y_1 & 0,794 & & Valid \\
\hline Y_2 & 0,706 & & Valid \\
\hline Y_3 & 0,683 & \multirow{2}{*}{0,2079} & Valid \\
\hline Y_4 & 0,766 & & Valid \\
\hline Y_5 & 0,706 & & Valid \\
\hline Y_6 & 0,801 & & Valid \\
\hline Y_7 & 0,799 & & Valid \\
\hline
\end{tabular}

Sumber: Data Primer

Berdasarkan Tabel 4.5 di atas, dapat dilihat nilai $\mathrm{r}_{\text {hitung }}$ untuk semua pernyataan variabel $\mathrm{Y}$ lebih besar dibandingkan dengan nilai $\mathrm{r}_{\text {tabel }}$ senilai $0.2079(\mathrm{df}=123)$. Dengan demikian, seluruh pernyataan variabel kinerja karyawan (Y) dinyatakan valid dan dapat digunakan dalam pengujian selanjutnya.

\section{Hasil Uji Reliabilitas}

Uji Reliablitas digunakan untuk mengetahui tingkat reliabel suatu alat ukur dengan menghitung kolerasi cronbach alpha dengan masing-masing butir pernyataan dalam satu variabel, dengan ketentuan $>0,6$ berarti reliabel dan $<0,6$ berarti tidak reliabel. 
4.6. Hasil Uji Reliabilitas

\begin{tabular}{|c|l|c|c|c|}
\hline No & \multicolumn{1}{|c|}{ Variabel } & $\begin{array}{c}\text { Cronbach's } \\
\text { Alpha }\end{array}$ & N of Items & Keterangan \\
\hline 1 & Kompetensi & 0,914 & 3 & Reliabel \\
\hline 2 & Motivasi & 0,840 & 5 & Reliabel \\
\hline 2 & Komunikasi & 0,810 & 5 & Reliabel \\
\hline 3 & Kinerja Karyawan & 0,872 & 7 & Reliabel \\
\hline
\end{tabular}

Sumber: Data Primer

Berdasarkan Tabel 4.6, diketahui nilai Cronbach's Alpha untuk variabel kompetensi adalah sebesar 0,914, variabel motivasi 0,840 , variabel komunikasi sebesar 0,810 , dan variabel kinerja karyawan sebesar 0,872 . maka dapat disimpulkan bahwa instrumen penelitian ini sudah reliabel karena nilai Cronbach's Alpha masing-masing variabel lebih besar dari 0,6

\section{Hasil Uji Asumsi Klasik}

\section{Hasil Uji Multikolinieritas}

Menurut Sugiyono (2016: 87) menyatakan bahwa gejala multikolinieritas dapat diketahui dengan menggunakan atau melihat tool uji yang disebut Variance Inflation Factor (VIF). Caranya adalah dengan melihat nilai masing-masing variabel bebad terhadap variabel terikatnya. Jika nilai VIF kurang dari 10, menunjukkan model tidak terdapat gejala multikolinieritas.

Tabel 4.7 Hasil Uji Multikolinieritas

Coefficients $^{\mathrm{a}}$

\begin{tabular}{|c|c|c|c|c|c|c|c|c|}
\hline \multirow{2}{*}{\multicolumn{2}{|c|}{ Model }} & \multicolumn{2}{|c|}{$\begin{array}{l}\text { Unstandardized } \\
\text { Coefficients }\end{array}$} & \multirow{2}{*}{\begin{tabular}{|c}
$\begin{array}{c}\text { Standardiz } \\
\text { ed } \\
\text { Coefficien } \\
\text { ts }\end{array}$ \\
Beta
\end{tabular}} & \multirow[t]{2}{*}{$\mathrm{t}$} & \multirow[t]{2}{*}{ Sig. } & \multicolumn{2}{|c|}{$\begin{array}{l}\text { Collinearity } \\
\text { Statistics }\end{array}$} \\
\hline & & B & $\begin{array}{l}\text { Std. } \\
\text { Error }\end{array}$ & & & & $\begin{array}{c}\text { Toleran } \\
\text { ce }\end{array}$ & VIF \\
\hline \multirow{4}{*}{1} & (Constant) & 5,041 & 1,112 & & 4,532 & , 000 & & \\
\hline & Kompetensi & ,423 & ,075 & ,410 & 5,640 & ,000 & ,403 & 2,480 \\
\hline & Motivasi & ,487 & 0,81 &, 450 & 5861 &, 000 & 0,451 & 1.911 \\
\hline & Komunikasi & ,636 & ,092 & ,504 & 6,930 &, 000 & ,403 & 2,480 \\
\hline
\end{tabular}

a. Dependent Variable: Kinerja Karyawan

Berdasarkan Tabel 4.7 diatas, dapat dilihat bahwa nilaiVariance Inflation Factor (VIF) dari masing-masing variabel Kompetensi motivasi dan komunikasi sebesar 2,480 < 10, dengan demikian dapat disimpulkan tidak terjadi multikolinearitas. 


\section{Hasil Uji Heteroskedastisitas}

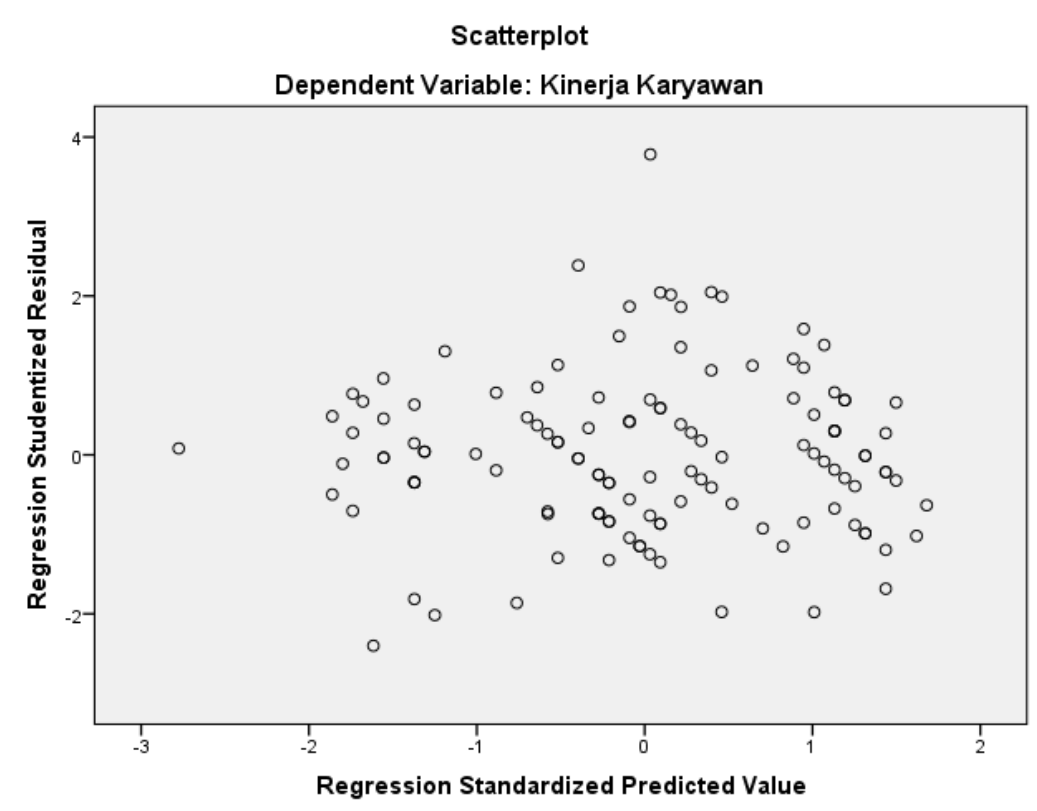

\section{Gambar 4.1 Grafik Scatter Plot}

Berdasarkan hasil grafik scatter plot diatas, terlihat bahwa titik-titik menyebar dan tidak membentuk pola tertentu yang jelas. Sehingga dapat disimpulkan bahwa pada model regresi tidak terjadi masalah heteroskedastisitas.

\section{Hasil Uji Koefisien Determinasi $\left(\mathbf{R}^{2}\right)$}

Koefisien determinasi $\left(\mathrm{R}^{2}\right)$ menunjukkan seberapa besar persentase variasi variabel independen yang digunakan dalam model mampu menjelaskan variasi variabel dependen. $\mathrm{R}^{2}$ sama dengan 0 , maka tidak ada sedikit pun persentase sumbangan pengaruh yang diberikan variabel independen terhadap variabel dependen, sebaliknya $\mathrm{R}^{2}$ sama dengan 1 , maka persentase sumbangan pengaruh yang diberikan variabel independen terhadap variabel dependen adalah sempurna.

Tabel 4.8 Hasil Uji Koefisien Determinasi $\left(\mathbf{R}^{2}\right)$ Model Summary

\begin{tabular}{|c|c|c|c|}
\hline Model & \multicolumn{1}{|l|}{ R Square } & Std. Error of the Estimate \\
\hline 1 &, $870^{\mathrm{a}}$ &, 840 & 2,070 \\
\hline
\end{tabular}

a. Predictors: (Constant), Kompetensi, Motivasi dan Komunikasi

Berdasarkan Tabel 4.8 dapat disimpulkan bahwa R Square $=0,840$ artinya Kompetensi, motivasi dan komunikasi berpengaruh sebesar $84 \%$ terhadap kinerja karyawan.

\section{Kompetensi berpengaruh terhadap kinerja karyawan}

Hasil penelitian ini telah membuktikan terdapat pengaruh gaya kepemimpinan terhadap kinerja karyawan. Melalui hasil perhitungan yang telah dilakukan diperoleh nilai $t_{\text {hitung }}(5,640)>t_{\text {tabel }}$ $(1,97944)$ dengan nilai siginifikansi $=0,000$ lebih kecil 0,05 maka Ho ditolak dan Ha diterima. Pengujian ini secara statistik membuktikan bahwa Kompetensi berpengaruh signifikan terhadap kinerja karyawan pada Rumah Sakit Swasta di Kota Batam. Hasil Penelitian ini sesuai dengan penelitian yang dilakukan oleh Wiguna (2015). 


\section{Motivasi berpengaruh terhadap kinerja karyawan}

Hasil penelitian ini telah membuktikan terdapat pengaruh motivasi terhadap kinerja karyawan. Melalui hasil perhitungan yang telah dilakukan diperoleh nilai $t_{\text {hitung }}(5,891)>t_{\text {tabel }}(1,97944)$ dengan nilai siginifikansi $=0,000$ lebih kecil 0,05 maka Ho ditolak dan Ha diterima. Pengujian ini secara statistik membuktikan bahwa motivasi berpengaruh signifikan terhadap kinerja karyawan pada Rumah Sakit Swasta di Kota Batam.

\section{Komunikasi berpengaruh terhadap kinerja karyawan}

Hasil penelitian ini telah membuktikan terdapat pengaruh komunikasi terhadap kinerja karyawan. Melalui hasil perhitungan yang telah dilakukan diperoleh nilai thitung $(6,930)>$ ttabel $(1,97944)$ dengan nilai signifikansi $=0,000$ lebih kecil 0,05 maka Ho ditolak dan Ha diterima. Pengujian ini secara statistik membuktikan bahwa komunikasi berpengaruh signifikan terhadap kinerja karyawan Rumah Sakit Swasta di Kota Batam. Hasil Penelitian ini sesuai dengan penelitian yang dilakukan oleh Lakoy (2015)

\section{Kompetensi motivasi dan komunikasi berpengaruh terhadap kinerja karyawan}

Hasil penelitian ini telah membuktikan terdapat pengaruh kompetensi dan komunikasi terhadap kinerja karyawan pada rumah sakit swasta di Kota Batam. Melalui hasil perhitungan yang telah dilakukan diperoleh nilai $F_{\text {hitung }}(173,900)>F_{\text {tabel }}(3,07)$ dan nilai signifikansi $=0,000<0,05$ maka Ho ditolak dan Ha diterima. Dengan ditolaknyan Ho dan diterimanya Ha, menunjukkan bahwa kompetensi motivasi dan komunikasi secara bersama-sama berpengaruh terhadap kinerja karyawan pada Rumah Sakit Swasta di Kota Batam. Hasil Penelitian ini sesuai dengan penelitian yang dilakukan oleh Hartono dan Rotinsulu (2015).

\section{KESIMPULAN}

Berdasarkan hasil penelitian dan pembahasan diatas, maka dibuat beberapa kesimpulan yaitu:

1. Berdasarkan hasil dari penelitian ini menyatakan bahwa Kompetensi berpengaruh positif dengan kinerja karyawan, yang diperoleh yaitu t hitung $>\mathrm{t}$ tabel, sehinga Ho ditolak dan Ha diterima artinya kompetensi berpengaruh positif dan signifikan terhadap kinerja karyawan pada Rumah Sakit Swasta di Kota Batam.

2. Berdasarkan hasil dari penelitian ini menyatakan bahwa motivasi dengan kinerja karyawan, yang diperoleh yaitu $\mathrm{t}$ hitung $>\mathrm{t}$ tabel, sehingga Ho ditolak dan Ha diterima artinya motivasi berpengaruh positif dan signifikan terhadap kinerja karyawan Rumah Sakit Swasta di Kota Batam

3. Berdasarkan hasil dari penelitian ini menyatakan bahwa komunikasi dengan kinerja karyawan, yang diperoleh yaitu $t$ hitung $>t$ tabel, sehingga Ho ditolak dan Ha diterima artinya komunikasi berpengaruh positif dan signifikan terhadap kinerja karyawan Rumah Sakit Swasta di Kota Batam

4. Berdasarkan hasil dari penelitian ini menyatakan bahwa kompetensi dan komunikasi dengan kinerja karyawan, yang diperoleh $\mathrm{f}$ hitung > f tabel, sehingga Ho ditolak dan ha diterima artinya kompetensi, motivasi dan komunikasi berpengaruh positif dan signifikan terhadap kinerja karyawan pada Rumah Sakit Swasta di Kota Batam. 


\section{DAFTAR PUSTAKA}

Anwar, Sanusi. (2018). Metode Penelitian Bisnis. Salemba Empat. Jakarta

Bangun, Wilson. (2014). Manajeman Sumber Daya Manusia. Erlangga. Bandung.

Burhanudin. (2015). Komunikasi Bisnis. Cetakan Pertama. Pustaka Pelajar. Yogyakarta.

Feriyanto dan Triana. (2015). Pengantar Manajemen. Cetakan Pertama. Mediatera. Yogyakarta.

Ghozali, Imam. (2014. Aplikasi Analisis Multivariate Dengan Program IBM SPSS 19. Edisi Kelima. Universitas Diponegoro. Semarang.

Lakoy, Amanda, Lakoy. (2015) Pengaruh Komunikasi, Kerjasama Kelompok, dan Kreativitas Terhadap Kinerja Karyawan Pada Hotel Aryaduta Manado. Jurnal Emba. Vol. 03 (03): 981 - 991.

Nazir, Mohammad. (2019). Metode Penelitiab. Ghalia Indonesia. Jakarta.

Noor. (2016). Metode Penelitian. Edisi Pertama. Kencana Prenada Media Group. Jakarta.

Rianse, Usman dan Abdi. (2008). Metodologi Penelitian Sosial dan Ekonomi (Teori dan Aplikasi). Alfabeta Bandung.

Sugiyono. (2016). Metode Penelitian Kuantitatif Kualitatif dan $R \& D$. Alfabeta. Bandung.

Sugiyono, (2014). Metode Penelitian Bisnis. Alfabeta. Bandung. 